\title{
EXOTIC PLANTS OF THE NORTHERN ROCKY MOUNTAIN ENVIRONMENTAL ZONES
}

\author{
Bryant Woods \\ Tad Weaver \\ Department of Biology \\ Montana State University \\ Bozeman
}

\section{Introduction}

Exotic plants occur in national parks and forests throughout the northern Rocky Mountains. We report here progress on a study to determine their physiological and ecological ranges within major environmental zones of the region. To date, we have clarified objectives, refined methodology, and sampled 80-85\% of initial sites chosen in Glacier NP. We begin data analysis in January, and will sample in both Grand Teton and Glacier in the coming summer.

\section{Objectives}

The unifying intent of our study is to provide park managers, and managers of other public lands in the Northern Rockies, with information that will contribute to their understanding of and attempts to control the spread of exotic plants. To this end, we have three specific objectives.

First, we are describing the distributions of major exotic plants on disturbed sites within the environmental zones found in the national parks of the region. This information on physiological range will help managers estimate exotics' potentials to move into areas which are now relatively exotic-free.

We also seek to assess the likelihood that exotics, once estabiished in disturbed areas within a particular environmental zone or habitat-type, will invade less disturbed or even climax native vegetation. Such information will provide managers with a basis for setting priorities for levels of and expenditures on control.

Finally, we hope to identify, for each habitat-type considered, native plants capable of becoming established and surviving in disturbed areas in competition with exotics. Such natives might provide managers with improved revegetation strategies, as well as a viable alternative to herbicide control.

\section{Methods}

The project design consists of two dimensions, one regional and the other local. The regional dimension addresses the question of exotic distribution within the major environmental zones of the two parks. It is based on the assumption that 
climax vegetation at a given site reflects a specific set of environmental conditions, and that wherever similar vegetation occurs, environmental conditions should be essentially the same. For Glacier, we are using the habitat-type systems of Pfister, et al. (1977) and Meuggler and Stewart (1989); we have not yet chosen a specific classification scheme for use in Grand Teton.

The local dimension addresses the issues of the ability of exotics established in disturbed areas along roadsides to invade less disturbed vegetation nearby, and the ability of natives to invade disturbed areas. Our model assumes that, due to the construction and maintainance of roads through natural areas, there potentially are four identifiable regions of ground paralleling roadsides between the edge of the pavement and the beginning of native vegetation, and that these regions differ enough in the degree of disturbance imposed upon them that there is a gradient of disturbance, heaviest at the roadside, through them. These four disturbance zones are (1) a zone from $1 / 2$ to one meter wide at the edge of the roadside, which is constantly disturbed by mowing, snow removal, compression by errant vehicles, overflow of gravel and tar from road maintainance, and addition of chemicals from passing traffic; (2) a zone occupying the downslope of the ditch (but not including the wet area at the bottom of the ditch), which receives the same sorts of disturbance as the above, although in lesser amounts; (3) a zone occupying the upslope of the ditch, which since the time of the profound disturbance of roadbuilding has remained fairly undisturbed; and (4) a zone beyond the ditch from which most aboveground vegetation was removed during roadbuilding, but the soil of which was mostly undisturbed.

The way in which these two dimensions guide the selection of sample sites can be illustrated by a discussion of the first summer's work in Glacier. We identified the habitat-types adjacent to all roads in the park, and selected widespread ones for closer study. Along the roads within each of the chosen habitat-types, 10 well-dispersed sites which exhibited the four zones discussed above were sought. (See Table 1 for habitat-types used, as well as types in which not all zones were available.) At each site, parallel $1 / 2$ by 25 meter plots were estabiished within each zone, and an additional plot was established in the contiguous native vegetation. Within each plot, presence, frequency and cover were recorded for all species.

At each sample site, then, we obtained data pertaining to each of our major objectives. A record of the presence of various exotics contributes to the delineation of their physiological range in terms of habitat-type. A comparison of their density and abundance through the various zones provides a measure of their ability to invade less disturbed areas and native vegetation. And noting the presence and abundance of specific natives in disturbance zones otherwise dominated by exotics will serve as a basis for predicting their success as competitors when used in reclamation.

\section{Results and Conclusions}

To date we have made no formal analysis of data collected in 1984. Thus the drawing of conclusions would be premature. The observations below, based on 
Table 1. Study sites in Glacier National Park. Numbers represent total plots in each habitat-type/disturbance zone. NA means not available.

\begin{tabular}{|c|c|c|c|c|c|}
\hline \multirow[t]{2}{*}{ Habitat-type } & \multirow[b]{2}{*}{1} & \multirow[b]{2}{*}{2} & \multicolumn{3}{|c|}{ Disturbance zones } \\
\hline & & & 3 & 4 & 5 \\
\hline \multicolumn{6}{|l|}{ Abies lasciocarpa- } \\
\hline Clintonia uniflora & 9 & 4 & 9 & 4 & 9 \\
\hline \multicolumn{6}{|l|}{ Abies lasciocarpa- } \\
\hline Xerophyllum tenax & 10 & 10 & 10 & 5 & 10 \\
\hline Aspen groveland & 8 & 8 & 8 & NA & 8 \\
\hline \multicolumn{6}{|l|}{ Festuca scabrella- } \\
\hline Festuca idahoensis & 10 & 10 & 10 & NA & 10 \\
\hline Subalpine meadow & 0 & 0 & 0 & 0 & 0 \\
\hline \multicolumn{6}{|l|}{ Thuja plicata- } \\
\hline Oplopanax horridum & 10 & 10 & NA & NA & 10 \\
\hline \multicolumn{6}{|l|}{ Tsuga heterophylla- } \\
\hline Clintonia uniflora & 10 & 10 & 10 & 10 & 10 \\
\hline
\end{tabular}


Glacier Park vegetation alone, are made with caution, and may require modification in future reports.

1. The undisturbed climax or subclimax vegetation of most habitat-types appears relatively resistant to invasion by exotics presently established nearby.

2. The Fescue grasslands on the east side of the park, however, may well be endangered by the spotted knapweed growing in abundance on road shoulders there. While knapweed in Glacier appears at this time to be restricted to disturbances, it is clearly invading grasslands of the same habitat-type in the Swan River Valley in places where there are no obvious signs of disturbance. The situation in Glacier bears close monitoring, and, given the destructive potential of knapweed invasions, may justify extensive control efforts now.

3. In most areas left relatively undisturbed after road-building, a process of plant succession to an assemblage of native species occurs.

4. Where disturbance is more or less constant, exotic species compose most, if not all, of the vegetation many years after the original disturbance. Naturalized exotic species of pasture grasses such as Bromus inermis, Phleum pratense and Poa pratensis are ubiquitous and persistant in these areas.

5. To this point in the study, we see but a few native species readily capable of establishing and maintaining themselves in disturbed areas.

\section{Future Plans}

We have budgeted to spend the winter on data reduction and manipulation. Releve tables will be built to contrast disturbed and native vegetation in successively less disturbed zones within each major habitat-type, and to contrast the exotic floras of different habitat-types. Our sampling procedures do not precisely identify levels of disturbance, so we will ordinate the data in order to describe changes in community composition along a composite disturbance gradient.

We will be based in Grand Teton NP in 1985, sampling according to the above model in that park, and in Yellowstone NP if time permits. Initial sampling in Glacier will be completed during a short trip in July or August.

\section{Literature Cited}

Mueggler, W. and W. Stewart. 1980. Grassland and Shrubland Habitat Types of Western Montana. USDA For. Ser. Gen. Tech. Rept. INT 66. 154 pages.

Pfister, R., B. Kovalchik, S. Arno and R. Presby. 1977. Forest Habit Types of Montana. USDA For. Ser. Gen. Tech. Rept. INT 34. 174 pages. 